\title{
The research and application of anchor foundation
}

\author{
Yongping $\mathrm{Li}^{1, \mathrm{a}}$, Shiming $\mathrm{Yan}^{2}$ \\ ${ }^{1}$ Northeast Dianli University, Jilin 132012, China \\ ${ }^{2}$ Northeast Dianli University, Jilin 132012, China
}

\begin{abstract}
The previous project in mountain area is often used in the ordinary rock digging foundation, the foundation of the general requirements of artificial digging, when the rock very good integrity and weathering degree is low, the time-consuming, low construction efficiency, low degree of mechanization. In order to change this situation, The study of rock bolt foundation specially set up, and the application in the engineering and the follow-up project, make it become the basic types of practical value in engineering.
\end{abstract}

\section{Introduction}

Tall mountain mountain and brought great difficulties to the tower foundation material transportation and construction work, the problem at the same time, but also the environmental protection. The previous project in mountain area is often used in the ordinary rock digging foundation, the foundation of the general requirements of artificial digging, when the rock very good integrity and weathering degree is low, the time-consuming, low construction efficiency, low degree of mechanization. In order to change this situation, the study of rock bolt foundation specially set up, and the application in the engineering and the follow-up project, make it become the basic types of practical value in engineering. By means of test and engineering application, we think of rock bolt foundation has the following advantages: make full use of the rock itself strength, strong ability to resist uplift; small amount of earthwork excavation, save steel and concrete;rock hole mechanized transport, less quantity, short construction period; does not destroy the original geological condition, slag less, is conducive to the Protect environment; save manpower and material resources, and has good social benefit and economic benefit, so the rock bolt foundation has very high application value in the mountains.

\section{Organization of the Text}

\subsection{The research and analysis of Anchor foundation.}

Commonly used in the transmission lines of rock anchor pile foundation type include straight anchor, bearing table, built-in type and anchor foundation, including direct anchor and bearing table were called rock bolt foundation in the engineering practice.

\footnotetext{
${ }^{a}$ Corresponding author: author@e-mail.org
}

When the rock bare rock hard breeze, can be directly called tower leg anchor bolt anchor into the rock anchor see Fig. 1. The anchor bar moderately weathered rock, using anchor into the rock, and on the anchor bar pouring pile caps, anchor bolt embedded in taichung, as shown in Fig. 2:

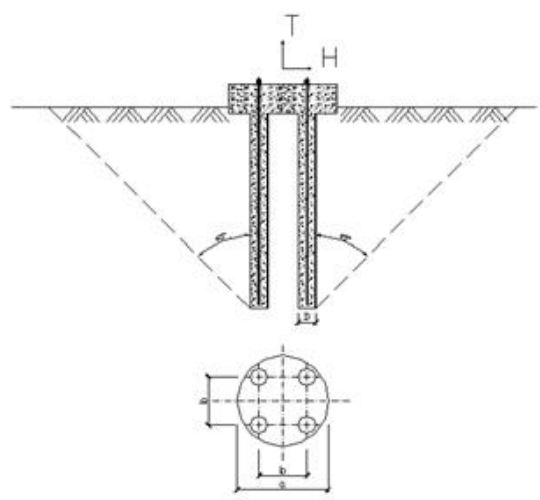

Figure 1.Vertical anchor

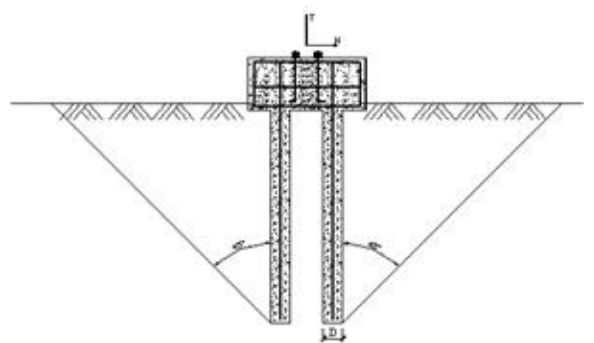

Figure 2.Cap type 
Due to the high compressive bearing capacity of rock mass, so the rock bolt is generally not down load calculation, when the design, only need to meet the requirements of drawing and stable. To anchor based on assumptions when pulling damage rock mass is by the dotted line as shown in the diagram below inverted cone as a hypothetical failure surface, so in when drawing design assumptions with uniform distribution in the cone surface generation such as limit shear force on the vertical component of the sum to resist pulling force. At the same time, should guarantee anchor bolt itself of the anchor bar or the tensile strength, anchor bar and anchor bolt and mortar bond strength or bolt and rock bond strength are both meet the requirements.

In order to ensure the reliability and rationality of the anchor based on the engineering practice, organization and implementation of the rock anchor foundation experiment, and practical applications in engineering, at the same time as the rock anchor foundation to further promote the use of accumulated experience in the transmission lines.

The experiment selected the two separately according to the rock properties of different kinds of typical rock test. The rocks of two types are strongly weathered granite and moderately weathered limestone. In each geological respectively for three straight single anchor bolt pulling and two straight type of anchor bolt is basic test.

Strongly weathered granite on three different depth on the basis of the single bolt type only do pull test, the test content is: anchor bar on the stress and deformation under the action of pulling force, anchor displacement and deformation under stress, the main column, anchor displacement of surrounding rock deformation. Strongly weathered granite on two different buried depth of the straight type of anchor bolt is based on simultaneous extraction and horizontal load test, the test content is: based on the level and bolt pulling force under the action of stress and strain of the foundation anchor bar, foundation displacement and deformation of the pile caps under stress, foundation displacement of surrounding rock deformation.

In moderately weathered rock is also based on the above test items. After each test to limit load are loaded until destruction.

In strongly weathered granite trials, five of the rock anchor foundation is shear failure of rock mass, it is an ideal result for rock bolt foundation, anchor bar and bond strength of the main column and the bond strength between concrete main column and the rock mass has reached the design requirements, at this time can make full use of the shear strength of rock mass itself to resist pulling force. Test data show that when the shear failure of rock mass, tau $\mathrm{s}$ value has reached $47 \mathrm{kN} / \mathrm{m} 2 \sim 58$ $\mathrm{kN} / \mathrm{m} 2$, this shows that: under the geological conditions of strong weathering granite gneiss using rock anchor foundation is reasonable and reliable.

In moderately weathered limestone experiment, three single anchor experiment foundation for bond damage, the main column shows the bedrock itself inherent strength is larger, and the other two socket bench test, no signs of damage in medium weathered limestone geological conditions, the bearing capacity of the rock anchor foundation is not controlled by shear failure of rock mass.

According to the test of the ultimate bearing capacity of the press "obvious turning point method" and "the ultimate load method" calculate the ultimate pull-out force, the results of numerical see the pull force test limit table. Compared with the test load data in the table, the anchor foundation has the very high reliability

under horizontal load, deformation of Rock anchor foundation is within the scope of the permit, explain rock anchor foundation has enough ability to resist horizontal load.

\subsection{Economical comparison}

In mountainous area, the application of the rock foundation and application of ordinary bolt foundation, anchor based not only on the construction craft is advanced, but also has more obvious advantages in the economic and social benefits. By ordinary rock excavation foundation and anchor foundation single-base all the data in the budget sheet, based in the indicators for the anchor bolt can verify all has the good economic efficiency.

Table 1. Ordinary rock excavation foundation and anchor foundation single-base budget.

\begin{tabular}{|c|c|c|c|c|c|c|}
\hline \multirow{2}{*}{ foundatjon } & \multicolumn{2}{|c|}{$\begin{array}{c}\text { cost of } \\
\text { materials }\end{array}$} & \multicolumn{2}{|c|}{ Installation fee } & \multirow{2}{*}{$\begin{array}{c}\text { freig } \\
\text { ht }\end{array}$} & \multirow{2}{*}{ total } \\
\hline & steel & $\begin{array}{l}\text { concr } \\
\text { ete }\end{array}$ & $\begin{array}{l}\text { constr } \\
\text { uction }\end{array}$ & $\begin{array}{c}\text { excava } \\
\text { tion }\end{array}$ & & \\
\hline $\begin{array}{c}\text { digging } \\
\text { foundation }\end{array}$ & 4510 & 3952 & 11064 & $\begin{array}{c}7295.0 \\
0\end{array}$ & $\begin{array}{c}780 \\
0\end{array}$ & 34621 \\
\hline $\begin{array}{l}\text { anchor } \\
\text { foundation }\end{array}$ & 4400 & 505 & 1556 & $\begin{array}{c}14040 . \\
00\end{array}$ & 900 & 21401 \\
\hline
\end{tabular}

Note: use more straight line tower foundation in this project are compared the economic benefits.

\subsection{The advantage of the anchor foundation}

The design on the basis of anchor bolt embedded in rock mass directly, make full use of the wholeness and completeness of the rock mass, foundation less dosage of concrete and steel consumption, make the foundation ontology cost reductions and has high economic benefit.

Based the surface part is small, the construction base level required is small, so quantity of earth-rock prescribing rarely, also need not open rock blasting, reduces the cost of earthwork quantity, reduce the damage to the original landform mountains, is advantageous to the ecological environment protection.

Anchor drilling machine is used for the anchor foundation, realized the mechanization of mountain foundation construction, a new construction technology, 
construction of the characteristics of fast speed, which can effectively shorten the construction period, improve the construction quality, reduce manpower requirements at the same time, reduce the labor intensity of workers, labor protection the job.

Anchor foundation is especially suitable for tall mountains, due to the advanced construction technology, construction base is small, the material province etc, and, ordinary difficulty for the rock foundation construction, construction site materials difficult to transport.

\subsection{Design of safeguard measures}

Through the research, bolt foundation in highly weathered and weathered rock tower have good applicability, mountain foundation design can play to their advantage.

Because of the huge influence of weathering degree of rock bedding joints and rock on bearing capacity of foundation, the existence of large discreteness, design personnel should be based on the surface of rock cover thickness, the stability of rock mass, rock weathering degree of firmness, bedding and fractures, etc., using the combination of full range leg length of iron tower foundation design.

Designers should be technology for construction personnel work before construction, to understand the design intention and the main design principle,master the design of the technical requirements for construction.

Construction should carry out the construction in strict accordance with the design drawings. Designers should base in place by examining trough.

\section{Conclusions}

The use of rock bolt foundation can save concrete material quantity and the amount of excavation, reduce the engineering investment. At the same time as little as possible to destroy the original topography, Protect environment and vegetation, reflects the good social benefit and economic benefit, and compared with the ordinary rock digging foundation has the obvious superiority .

1. Ministry of Construction of the People's Republic of China, GB50011-2010 code for seismic design of buildings[S], Beijing, 2010

2. E. Savory,G.A.R. Parke,P. Disney,N. Toy.Windinduced transmission tower foundation loads: A field study-design code comparison[J].Journal of Wind Engineering \& Industrial Aerodynamics,2007,28(24):125 126

3. Shili Gong, Handbook for seismic design of buildings[M], Beijing, 2002

4. Ling Zhang,Minghua Zhao,Wei He. Working mechanism of two-directionreinforced composite foundation.J.Cent.South Univ.Technol,2007, 589594

5. [5] Wakamastu K.Liquefaction case histories of voleanic deposits[A].Proe.lstInt. Conf.on Earthquake Geoteehnical Engineering[C].1995.19- 23 